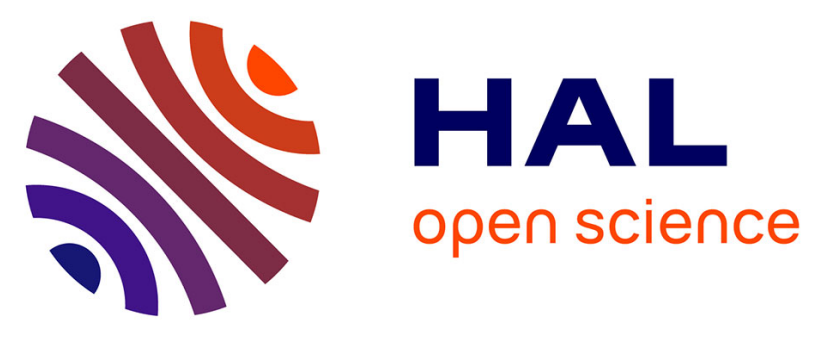

\title{
Relapsing encephalopathy with cerebellar ataxia are caused by variants involving p.Arg756 in ATP1A3
}

Pascal Sabouraud, Audrey Riquet, Marie-Aude Spitz, Kumaran Deiva, Sona

Nevsimalova, Cyril Mignot, Gaëtan Lesca, Nathalie Bednarek, Diane

Doummar, Christine Pietrement, et al.

\section{To cite this version:}

Pascal Sabouraud, Audrey Riquet, Marie-Aude Spitz, Kumaran Deiva, Sona Nevsimalova, et al.. Relapsing encephalopathy with cerebellar ataxia are caused by variants involving p. Arg756 in ATP1A3. European Journal of Paediatric Neurology, 2019, 23, pp.448 - 455. 10.1016/j.ejpn.2019.02.004 hal03485977

\section{HAL Id: hal-03485977 \\ https://hal.science/hal-03485977}

Submitted on 20 Dec 2021

HAL is a multi-disciplinary open access archive for the deposit and dissemination of scientific research documents, whether they are published or not. The documents may come from teaching and research institutions in France or abroad, or from public or private research centers.
L'archive ouverte pluridisciplinaire HAL, est destinée au dépôt et à la diffusion de documents scientifiques de niveau recherche, publiés ou non, émanant des établissements d'enseignement et de recherche français ou étrangers, des laboratoires publics ou privés.

\section{(ㄷ)(1) $\$$}

Distributed under a Creative Commons Attribution - NonCommerciall 4.0 International 


\section{Relapsing encephalopathy with cerebellar ataxia are caused by variants involving p.Arg756 in ATP1A3}

Pascal Sabouraud ${ }^{\text {a* }}$, Audrey Riquet ${ }^{\mathrm{b}}$, Marie-Aude Spitz $^{\mathrm{c}}$, Kumaran Deiva $^{\mathrm{d}}$, Sona Nevsimalova ${ }^{\mathrm{e}}$, Cyril Mignot $^{\mathrm{f}}$, Gaëtan Lesca $^{\mathrm{g}}$, Nathalie Bednarek ${ }^{\mathrm{h}}$, Diane Doummar' , Christine Pietrement' ${ }^{j}$, Vincent Lauge ${ }^{k}$

${ }^{a}$ Department of Pediatrics, American Memorial Hospital, CHU Reims, Reims, France.

${ }^{\mathrm{b}}$ Department of Pediatric Neurology, Hopital Roger Salengro, CHU Lille, Lille, France.

${ }^{c}$ Department of Pediatrics, Strasbourg University Hospital, Strasbourg, France.

${ }^{d}$ Department of Pediatric Neurology, AP-HP, Hôpital Bicêtre, Paris, France

${ }^{\mathrm{e}}$ Department of Neurology, 1st Medical Faculty, Charles University, Prague, Czech Republic.

${ }^{\dagger}$ Department of Genetics, Groupe Hospitalier Pitié Salpêtrière, AP-HP, Paris, France.

${ }^{9}$ Department of Medical Genetics, Hospices Civils de Lyon, Lyon, France.

${ }^{\mathrm{h}}$ Department of Pediatrics, American Memorial Hospital, CHU Reims, Reims, France.

'Department of Pediatric Neurology, AP-HP, Hôpital Armand Trousseau, Paris, France.

${ }^{j}$ Department of Pediatrics, American Memorial Hospital, CHU Reims, Reims, France. 
${ }^{k}$ Department of Pediatrics, Hôpitaux Universitaires de Strasbourg, Strasbourg, France.

* Corresponding author: Pascal Sabouraud, Service de pédiatrie, American Memorial Hospital, 47 rue Cognacq-Jay 51092 Reims Cedex, France. psabouraud@chu-reims.fr tel +33 3267833 82, Fax +33 326788262

email addresses of co-authors :

Audrey Riquet : audrey.dayez@chru-lille.fr

Marie-Aude Spitz : marie-aude.spitz@chru-strasbourg.fr

Kumaran Deiva : kumaran.deiva@bct.aphp.fr

Sona Nevsimalova : sona.nevsimalova@lf1.cuni.cz

Cyril Mignot : cyril.mignot@aphp.fr

Gaëtan Lesca : gaetan.lesca@chu-lyon.fr

Nathalie Bednarek : nbednarek@chu-reims.fr

Diane Doummar : diane.doummar@aphp.fr

Christine Pietrement : cpietrement@chu-reims.fr

Vincent Laugel : vincent.laugel@chru-strasbourg.fr 
Abstract

Mutations in ATP1A3 lead to different phenotypes having in common acute neurological decompensation episodes triggered by a specific circumstance and followed by sequelae. Alongside Alternating Hemiplegia of Childhood (AHC), Rapid-onset Dystonia Parkinsonism (RDP) and Cerebellar ataxia, Areflexia, Pes cavus, Optic atrophy, Sensorineural hearing loss syndrome (CAPOS), a new Relapsing Encephalopathy with Cerebellar Ataxia (RECA) phenotype was published in 2015. We describe herein eight new pediatric cases. Most of them had no specific history when the first neurological decompensation episode occurred, before the age of 5 years, triggered by fever with severe paralytic hypotonia followed by ataxia with or without abnormal movements. Neurological sequelae with ataxia as the predominant symptom were present after the first episode in three cases and after at least one subsequent relapse in five cases. Five of the eight cases had a familial involvement with one of the two parents affected. The phenotype-genotype correlation is unequivocal with the causal substitution always located at position 756. The pathophysiology of the dysfunctions of the mutated ATPase pump, triggered by fever is unknown. Severe recurrent neurological decompensation episodes triggered by fever, without any metabolic cause, should lead to the sequencing of ATP1A3.

\section{Keywords}

ATP1A3

Ataxia

Movement disorder

Child 
Introduction

After discovering mutations in ATP1A3, the gene encoding the a3-subunit of the $\mathrm{Na}+/ \mathrm{K}+-\mathrm{ATP}$ ase pump, in RDP (MIM 128235) in 2004 (1), other phenotypes were subsequently described related to other pathogenic variants of this gene: AHC (MIM 614820) in 2012 (2,3), CAPOS (MIM 601338) in 2014 (4), early forms of intellectual deficits with epilepsy and ataxia in 2015 (5). A new phenotype with acute and recurrent episodes of neurological distress occurring in childhood and responsible for chronic cerebellar ataxia was described in an adult in 2015 (6) and called RECA. The p.Arg756Cys pathogenic variant of ATP1A3 was reported in that context. We report herein eight new pediatric cases of RECA with a substitution of the same arginine at position 756 .

Patients and methods

This retrospective study has been performed according to the French regulations and respected all the legal conditions of its realization. The constitution of the patient file for this study is covered by the simplified methodology MR003 ( $\mathrm{N}^{\circ}: 2016198$ v 0) delivered by the National Commission for Data Protection (CNIL).

\section{Case report 1}

This 16-year-old girl is the youngest of 3 siblings, born at full term with normal clinical birth parameters. At 21 months during a fever, she presented with severe hypotonia and areflexia leading to gait impairments with a spontaneous recovery and normal neurological examination after 4 weeks. At the age of 4.5 
years after a virus with fever, she experienced a new acute neurological decompensation episode with ataxia associated with dysmetria, dysarthria, areflexia with preserved consciousness. Lactic acid levels in the cerebrospinal fluid (CSF) and brain MRI were normal. The clinical recovery was slow and incomplete with the persistence of an isolated cerebellar ataxia. Four months later, during a fever, a third neurological decompensation episode occurred associating severe hypotonia, aggravation of the pre-existing ataxia, areflexia, swallowing disorders, mutism, dystonic movements of the upper limbs and without altered consciousness. After 5 months, ataxia, dysarthria, swallowing disorders were still present, but autonomous gait was possible. At the age of 16 years autonomous gait remains limited. Sequelae include such dysarthria, fine motor skills disorders and decreased writing speed. The clinical picture of the patient does not include deafness or ophthalmological disorders.

Respiratory chain activity with assessment of the pyruvate dehydrogenase activity on fibroblasts was normal. Brain MRI at the age of 11 years was normal. The electromyogram performed in light of flat hands and flat valgus feet showed signs of distal chronic denervation. The sequencing of ATP1A3 identified a c.2267G>A pathogenic variant (p.Arg756His). The family genetics study led to the conclusion of a de novo mutation.

\section{Case report 2}

This 12-year-old boy with no family history, born at full term with an intrauterine growth restriction, presented with normal psychomotor development. At 17 months during a fever he presented with severe hypotonia with loss of gait, mutism, without altered consciousness. A few days later the neurological 
examination found an ataxia with left hemineglect. In one month the clinical recovery was complete. The metabolic analysis, brain $\mathrm{MRI}$, and $\mathrm{EEG}$ were normal. Serology for Influenza A virus was positive. Seven months later at the age of 24 months, in a context of 48 hours of acute viral gastroenteritis with fever, he presented a new neurological episode associating ataxia with frequent falls, abnormal choreiform movements of the head and limbs, dysarthria, and hypotonia. The recovery was incomplete with a persistent ataxia. At the age of 6 years and 5 months, after a viral tonsillitis with fever, there was a new decompensation episode with aggravation of his ataxia, reappearance of the choreiform movements along with dysarthria and areflexia. Brain MRI and fundus examination were normal. A new metabolic assessment, including the activity of the respiratory chain on muscle and fibroblasts, showed no abnormality. Screening for the main mitochondrial mutation was negative. At the age of 10 years, additional examinations including nerve conduction studies with electromyogram (EMG), pointed to a motor axonal neuropathy. At the age of 12 years, the ataxia and choreiform movements were still present along with the dysarthria, the functional improvement was slow.

At the examination there was no deafness or pes planus and no associated cognitive disorders. The sequencing of ATP1A3 revealed a heterozygous de novo pathogenic variant c.2267G>A (p.Arg756His).

\section{Case report 3}

This 4-year-old boy, born at full term from a twin pregnancy had no specific perinatal history. His father has a motor disability diagnosed as "postencephalitic cerebral palsy". At the age of 2 years, this man presented with 
altered consciousness in the context of a high fever, associated with symptoms that were similar to those observed in his son. At the age of 44 years the father shows dysarthria, generalized dystonia predominant to the upper limbs, limited gait autonomy requiring the use of a wheelchair. At 16 months, during a feverish episode, his son presented with a severe neurological picture associated with altered consciousness, hypotonia, cerebellar signs with ataxia and dysarthria, swallowing disorders with hypersalivation, left hemiparesis, along with abnormal dystonia-like movements predominant to the upper limbs and on the left side associated with choreiform movements. The etiologic evaluation (brain MRI, lumbar puncture screening for neurotropic viruses, levels of ammonia, screening for toxic agents, EEG) was negative. The episode resolved spontaneously in one week. At the age of 3 years and 4 months during a benign febrile illness the child was hospitalized for a new severe and sudden neurological decompensation episode. The examination found hypotonia, mutism, swallowing disorders with hypersalivation, ataxia, dystonic and choreiform movements of the upper limbs, episodes of upward eye deviation similar to oculogyric crisis and bradykinesia. There was altered consciousness, no dysautonomia, and no oculomotor disorders. Deep tendon reflexes were present and symmetrical. The brain MRI remained normal. The study of the intermediary metabolism did not reveal any specificity. In the cerebral spinal fluid (CSF), the concentration of lactates and pyruvates and the profile of neurotransmitters were both normal, the screening for neurotropic viruses and Lyme disease was negative. The CSF/serum glucose ratio did not indicate a Glucose transporter type 1 (GLUT1) deficiency syndrome. The EEG was normal and the fundus examination did not unveil optic atrophy. At the age of 4 years 
and 3 months, there was still a dysarthria, dystonia of the upper limbs, choreiform movements, with a fluctuation of the symptoms. Running was possible, his left hand regained function and his speech had improved, the akinesia had decreased. No associated cognitive disorders were present. The sequencing of ATP1A3 revealed in our patient and his father a heterozygous c.2267G>A (p.Arg756His) pathogenic variant.

\section{Case report 4}

Patient 4 is the daughter of the woman who was reported as the first patient with RECA (6). The father of patient 4 had a recessively inherited spastic paraparesis. Patient 4 was born prematurely at 34 weeks of gestation with normal growth parameters and an Apgar score of 9 and 10 at 1 and 5 minutes, respectively. She had no prematurity complications, walked at 23 months and was always limited for running. Her language developed normally and she had no difficulties in her first years of school. At the age of 5.5 years, during an ordinary fever, likely a viral infection, she suddenly became unable to speak and eat. Her father reported that she was quickly able to eat again but her speech remained severely impaired after this episode. The will to communicate was still present, she was still able to shout and cry but had severe dysarthria and difficulties sticking her tongue out, puff her cheeks and blow through a straw. Both the brain MRI and EEG at 6 years were normal. She had intensive speech therapy for three years. At the age of 7.5 years, patient 4 was able to walk and use her hands and write without difficulties. Her voice was weak and her speech incomprehensible. She had limited voluntary movements of the tongue and cheeks, but did not present with facial paresis or oculomotor impairment. Her 
height $(121.5 \mathrm{~cm})$, weight $(22.5 \mathrm{~kg})$ and occipitofrontal circumference $(52 \mathrm{~cm})$ were normal. Two years later, there was little improvement and she had not had any relapses. Molecular testing for the c.2266C >T (p.Arg756Cys) pathogenic variant found in her mother revealed that she had inherited the variant. Her maternal grandmother stated that disease manifestations in her grand-daughter were identical to her daughter's when she was a child.

\section{Case report 5}

This 6-year-old girl presented with ataxia associated with choreiform movements. There was no intellectual impairment and no learning difficulty in school. Her 32-year-old mother, showing no sign of cognitive impairment, presented a severe neurological clinical picture diagnosed as viral encephalitis at the age of 5 years leading to ataxia, dysarthria and some choreiform movements which remained stable ever since. Her epilepsy required a treatment with Valproate until the age of 18 years. There was no specific family history or consanguinity. The personal history of the daughter was eventless with a normal psychomotor development: she was able to sit unaided at 7 months, to walk at 22 months and spoke her first words at 18 months. The first episode occurred at the age of 2 years during a benign febrile illness with ataxia that regressed in an incomplete manner. At the age of 3 years a second episode happened during a febrile illness with aggravation of the ataxia and dysphasia which improved only slowly. The EEG and CSF were normal during the first episode. Two brain MRIs showed a slight hyperintense signal on FLAIR sequences in the left cerebellar peduncle without any other abnormality. The 
Next Generation Sequencing of a gene panel unveiled a c.2267G>A (p.Arg756His) pathogenic variant also found in the mother.

\section{Case report 6}

After a normal psychomotor development, this 26-month-old girl presented with major hypotonia, left facial paralysis, dysarthria and swallowing difficulties during a febrile episode. Results from the CSF and imaging were normal. The recovery was slow with ataxia and tremors, choreiform movements, dystonia, dysarthria and moderate intellectual deficiency. A drug-resistant epilepsy started at the age of 3 years with absences then generalized tonic-clonic seizures and frequent status epilepticus. A c.2266C>T (p.Arg756Cys) pathogenic variant in ATP1A3 was found by exome sequencing. The variant was not present in any of the parents. At the age of 22 years she had not presented with recurrent episodes.

\section{Case report 7}

This 8-year old girl presented with congenital ataxia (walked at the age of 24 months with persistent instability) and normal intellectual development. Her 36year-old mother presented at the age of 27 months with a measles-induced encephalitis, persisting cerebellar signs and a second neurological degradation at the age of 10 years in the context of a pyelonephritis. The examination of the adult mother showed an ataxia associated with cerebellar and choreiform dysarthria. At the age of 3.5 years, during a febrile episode the child presented with an acute neurological episode associating hypotonia, ataxia, dysarthria, dysmetria and oculomotor apraxia. CSF, metabolic testing, brain MRI were 
normal. The recovery was complete within a few weeks with a return to the original state (moderate ataxia). Nevertheless, the clinical examination at the age of 7 years still found a cerebellar intention tremor. The sequencing of ATP1A3 led to the identification of a c.2267G>A (p.Arg756His) pathogenic variant, in the child and her mother.

\section{Case report 8}

This 8 year-old girl has shown impaired fine motor skills and intention tremor since the age of 3 years. Her 35-year-old mother had a febrile coma at the age of 3 years, with a recovery only one year later for gait, language and autonomous feeding. The examination of the adult mother showed cerebellar symptoms and choreoathetosis. At the age of 5 years, during a febrile episode, the child presented with a severe neurological episode associating hypotonia, ataxia, and choreiform facial movements. The brain MRI was normal, the recovery was achieved in a few weeks, but the dysarthria persisted. A study of ATP1A3 evidenced a c.2267G>A (p.Arg756His) pathogenic variant in the child and her mother.

\section{Discussion}

Similarly to all pathologies involving ATP1A3, this RECA phenotype is characterized by recurrent neurological decompensation episodes triggered by a specific event and leading to neurological sequelae. Based on the study of our 8 cases (Table 1) and the 16 cases from the literature (Table 2)(6-14), we can validate and describe the RECA phenotype. Some cases in the literature were 
described as an intermediate phenotype and can now be classified as the RECA phenotype $(7,8)$.

In two of our cases and two cases from the literature $(10,11)$, neurological abnormalities (ataxia, tremor) or psychomotor delay preceded the first decompensation.

Fever was the triggering factor for these episodes in all our cases and in 28 out of 33 cases reported in the literature. This fever was from viral origin with no specific markers.

In all the cases, the age at the first severe episode ranged between 8 months and 5.5 years, $2 / 3$ of the cases had their first episode before the age of 2 years. Relapses occurred most often before the age of 5 years with the exception of an episode at the age of 34 years in the case reported by Dard et al. (6). The clinical pictures of these episodes were very similar with severe hypotonia, sometimes associated to areflexia, mutism and swallowing troubles, without altered consciousness. Ataxia, dysarthria, sometimes choreoathetosic or dystonic movements usually appeared quickly after the onset of the first signs. Pyramidal tract signs, seizures and abnormal eye movements could be part of the clinical picture. Altered consciousness, lethargy, lack of reaction, bradykinesia, and paraparesis were sometimes reported in the most severe forms, especially in young children. Similarly, bulbar dysfunction symptoms can vary in their severity: from simple drooling to the inability to feed oneself, dysarthria up to complete mutism. The clinical picture is sometimes less severe with isolated ataxia that improves over a few days or an aggravation of the sequelae during recurrent decompensation episodes in older children. Ataxia during these episodes seems to be a common symptom to all RECA cases 
described (11/14 in our cases), sometimes diagnosed after a few days when the hypotonia has improved. Some previous reports $(11,13)$ have emphasized the predominantly weakness in the clinical picture and for these cases Yano et al. have proposed the term FIPWE for fever-induced paroxysmal weakness and encephalopathy: we believe that FIPWE and RECA are largely overlapping or similar phenotypes and suggest that the term RECA be used for all these cases.

Each decompensation is typically followed by a phase of slow and often partial recovery. Neurological sequelae set in after the first or second neurological episode. These sequelae can get worse or remain stable after a relapse. These consist mostly of ataxia, dysarthria and abnormal movements (dystonia or choreiform). Cognitive sequelae, epilepsy, nystagmus, hemiplegia were rarely reported.

Four cases in our series (cases 4, 6, 7 and 8), similarly to 3 cases in the literature $(9,10,13)$ had only one decompensation episode. In case 4 , the mother was diagnosed with RECA and had a mutation of ATP1A3. Her daughter decompensated at the age of 5 with a specific bulbar phenotype associated transient dysphagia and severe persistent dysarthria.

Severe hypotonia, mutism, dysarthria often described during the episodes point to a likely cerebellar involvement, a notion that was integrated by Dard et al. (6) who proposed the term of relapsing encephalopathy with cerebellar ataxia. An involvement of the basal ganglia and brain stem is possible, especially in light of the abnormal movements. An impairment of motoneuron activity is another hypothesis to explain the hypotonia, and lack of reaction. The only abnormality found on the MRI was an atrophy of the cerebellum $(6,9)$. Differential diagnosis 
includes post-infectious encephalitis, post-infectious cerebellitis and GuillainBarre syndrome. The recurrence of paroxysmal neurological episodes can also point to a metabolic disorder, especially a mitochondrial cause, pyruvate dehydrogenase complex deficiency, GLUT1 deficiency syndrome, mutation of CACNA1.

In AHC triggering factor have previously been reported including excitement and other types of physical and emotional stress for acute episodes in the majority of patients, and fever, discontinuation of flunarizine and status epilepticus for developmental deterioration in a significant minority of patients $(15,16)$. Episodes are essentially characterized by hemiparesis or abnormal ocular movements in newborns with a multiphasic evolution at first with a succession of severe neurological episodes, lasting from a few minutes to a few hours, characterized by hemiplegia often alternating from one side to the next, and asymmetric dystonic postures disappearing when sleeping (17-20). In RDP, various triggers such as benign trauma, emotional stress, febrile illness may be present. The clinical symptoms evolve over a few days to a few weeks with, in addition to the dystonia with rostrocaudal gradient of symptoms, bradykinesia and balance disorders with bulbar dysfunctions (dysphagia, dysarthria) with an aggravation at first then getting stable with a progression towards chronicity that can associate psychiatric and cognitive disorders, dysarthria and ataxia (17-19).

The CAPOS syndrome known since 1996 (21), was only linked to ATP1A3 mutations in 2014 (4). Since then, about twenty cases were reported, all related to one c.2452G>A (p.Glu818Lys) pathogenic variant. CAPOS and RECA share the same evolution process with recurrent severe decompensation episodes 
and fever is the triggering factor in both cases. The symptoms of the decompensation episodes are very similar with hypotonia, areflexia and ataxia, starting between the age of 6 months and 5 years (22). However, the sequelae characteristics after one or 2 decompensations episodes, around the age of 5-6 years old, are different with deafness, optic atrophy and often pes cavus for CAPOS (22). None of these three symptoms were described in cases of RECA. All phenotypes related to ATP1A3 are linked to the presence of a heterozygous mutation in the gene and all cases described for RECA are related to a heterozygous substitution of the arginine 756 of the ATP1A3 protein (p.Arg756His, p.Arg756Cys or p.Arg756Leu). Too few cases have been reported to evidence phenotype differences between these 3 mutations, as suggested by Yano et al. (13) and Nakamura et al. (14). This substitution can be due to autosomal dominant inheritance or be de novo. In the literature, no patient presented with one of these 3 mutations without having RECA, outside of the 2 cases insufficiently described by Viollet et al. (23). Two families with mosaicism in ATP1A3-related disorders were recently described (9) with its consequences on genetic counseling.

ATP1A3 encodes the alpha-3 catalytic subunit of the $\mathrm{Na}+/ \mathrm{K}+$ ATPase transmembrane ion pump, which is selectively expressed in neurons, especially in the cerebellum and basal ganglia $(24,25)$. The analysis of the ATP1A3 pathogenic variants reported so far suggests a strict genotype-phenotype correlation. Mutations responsible for the different clinical phenotypes are distinct $(3,26)$ : AHC and RDP phenotypes can be caused by mutations of the same amino acid but with different substitutions, CAPOS cases are linked to a single missense variant (p.Glu818Lys) and we showed that RECA cases are 
specifically caused by substitutions of the arginine 756 . This arginine 756 is part of a conserved domain between the transmembrane domains IV and V, located in a cytoplasmic region of the protein (27). Substitutions of nearby glycine 755 and isoleucine 758 were reported to cause AHC and RDP respectively (3), suggesting that very subtle molecular changes may trigger different clinical phenotypes.

It has been shown in C. elegans models that heterozygous variants introduced into the ortholog of ATP1A3 could dominantly modify the ATPase activity and significantly modulate neuronal excitability by altering intracellular proton concentration (28). Different variations induce various modifications in the binding and transport of $\mathrm{Na}+$ and $\mathrm{K}+$ ions : the affinity of the $\mathrm{Na}+/ \mathrm{K}+-\mathrm{ATPase}$ for cytoplasmic $\mathrm{Na}+$ without a disturbance of $\mathrm{K}+$ binding could be crucial in RDP whereas a disturbed affinity for $\mathrm{K}+$ could lead to AHC phenotype (29-31). Different variations could also selectively affect the function of the $\mathrm{Na}+/ \mathrm{K}+$ ATPase transmembrane ion pump or the overall quantity of the protein (2). It has been shown that in $\mathrm{AHC}$ the most frequent mutation results in failure of fast spiking inhibitory interneuron firing which would be expected to lead to sustained marked excitability and to excitotoxicity (32). CAPOS mutations cause a weaker voltage dependence of the pumping rate, a stronger inhibition by cytoplasmic $\mathrm{K}+$ than the wild type enzyme, and most importantly reduced $\mathrm{Na}+$ affinity of the cytoplasmic-facing sites precluding proper pump activation (33). Interestingly, it was also shown that some missense mutations in Drosophila orthologs of these ATPases could elicit a temperature-sensitive ionic leakage through the membrane in a dominant gain-of-function manner (34). In Drosophila, these mutations led to a temperature-sensitive discoordination. The 
same mechanism could well account for the fever-dependent symptoms in human patients carrying similar mutations. Specific neurophysiological studies modelling variants at Arg756 will be needed to test whether these mechanisms could be at stake to account for the RECA phenotype.

\section{Conclusion:}

The RECA phenotype is characterized by recurrent episodes of acute neurological decompensations, triggered by fever, with severe hypotonia, lack of reaction, followed by ataxia associated with abnormal movement disorders. The patient can recover after the first flare-up or retain sequelae that worsen during the subsequent neurological episodes. Sometimes the diagnosis can be made after one neurological decompensation episode when a parent is also affected. The triggering fever, relapses with sequelae should prompt the screening of the ATP1A3 gene, especially when respiratory chain analysis is negative. No preventive treatment is available to avoid new neurological episodes and aggravation of the neurological sequelae

\section{Acknowledgements}

This research did not receive any specific grant from funding agencies in the public, commercial, or not-for-profit sectors. The authors express their gratitude to Dr E. Panagiotakaki for her contribution to the diagnosis of one patient of the series and to the field of ATP1A3 diseases.

1. de Carvalho Aguiar P, Sweadner KJ, Penniston JT, Zaremba J, Liu L, Caton M, et al. Mutations in the $\mathrm{Na}+\mathrm{K}+-\mathrm{ATPase}$ alpha3 gene ATP1A3 are associated with rapid-onset 
dystonia parkinsonism. Neuron. 2004 Jul 22;43(2):169-75.

2. Heinzen EL, Swoboda KJ, Hitomi Y, Gurrieri F, Nicole S, de Vries B, et al. De novo mutations in ATP1A3 cause alternating hemiplegia of childhood. Nat Genet. 2012 Sep;44(9):1030-4.

3. Rosewich H, Thiele H, Ohlenbusch A, Maschke U, Altmüller J, Frommolt P, et al. Heterozygous de-novo mutations in ATP1A3 in patients with alternating hemiplegia of childhood: a whole-exome sequencing gene-identification study. Lancet Neurol. 2012 Sep;11(9):764-73.

4. Demos MK, van Karnebeek CD, Ross CJ, Adam S, Shen Y, Zhan SH, et al. A novel recurrent mutation in ATP1A3 causes CAPOS syndrome. Orphanet J Rare Dis. 2014 Jan 28;9:15.

5. Paciorkowski AR, McDaniel SS, Jansen LA, Tully H, Tuttle E, Ghoneim DH, et al. Novel mutations in ATP1A3 associated with catastrophic early life epilepsy, episodic prolonged apnea, and postnatal microcephaly. Epilepsia. 2015 Mar;56(3):422-30.

6. Dard R, Mignot C, Durr A, Lesca G, Sanlaville D, Roze E, et al. Relapsing encephalopathy with cerebellar ataxia related to an ATP1A3 mutation. Dev Med Child Neurol. 2015 Dec;57(12):1183-6.

7. Brashear A, Mink JW, Hill DF, Boggs N, McCall WV, Stacy MA, et al. ATP1A3 mutations in infants: a new rapid-onset dystonia-Parkinsonism phenotype characterized by motor delay and ataxia. Dev Med Child Neurol. 2012 Nov;54(11):1065-7.

8. Fornarino S, Stagnaro M, Rinelli M, Tiziano D, Mancardi MM, Traverso M, et al. Paroxysmal features responding to flunarizine in a child with rapid-onset dystoniaparkinsonism. Neurology. 2014 Jun 3;82(22):2037-8.

9. Hully M, Ropars J, Hubert L, Boddaert N, Rio M, Bernardelli M, et al. Mosaicism in ATP1A3-related disorders: not just a theoretical risk. Neurogenetics. 2017 Jan;18(1):238.

10. Jaffer F, Fawcett K, Sims D, Heger A, Houlden H, Hanna MG, et al. Familial childhood-onset progressive cerebellar syndrome associated with the ATP1A3 mutation. Neurol Genet [Internet]. 2017 Mar 27;3(2). Available from:

http://www.ncbi.nlm.nih.gov/pmc/articles/PMC5367920/

11. Kanemasa H, Fukai R, Sakai Y, Torio M, Miyake N, Lee S, et al. De novo p.Arg756Cys mutation of ATP1A3 causes an atypical form of alternating hemiplegia of childhood with prolonged paralysis and choreoathetosis. BMC Neurol. 2016 Sep $15 ; 16: 174$.

12. Nicita F, Travaglini L, Sabatini S, Garavaglia B, Panteghini C, Valeriani M, et al. Childhood-onset ATP1A3-related conditions: Report of two new cases of phenotypic spectrum. Parkinsonism Relat Disord. 2016 Sep;30:81-2.

13. Yano ST, Silver K, Young R, DeBrosse SD, Ebel RS, Swoboda KJ, et al. FeverInduced Paroxysmal Weakness and Encephalopathy, a New Phenotype of ATP1A3 Mutation. Pediatr Neurol. 2017 Aug;73:101-5.

14. Nakamura Y, Hattori A, Nakashima M, Ieda D, Hori I, Negishi Y, et al. A de novo p.Arg756Cys mutation in ATP1A3 causes a distinct phenotype with prolonged weakness and encephalopathy triggered by fever. Brain Dev. 2018 Mar;40(3):222-5.

15. Mikati MA, Kramer U, Zupanc ML, Shanahan RJ. Alternating hemiplegia of childhood: clinical manifestations and long-term outcome. Pediatr Neurol. 2000 Aug;23(2):134-41.

16. Sasaki M, Ishii A, Saito Y, Morisada N, Iijima K, Takada S, et al. Genotypephenotype correlations in alternating hemiplegia of childhood. Neurology. $2014 \mathrm{Feb}$ 11;82(6):482-90. 
17. Heinzen EL, Arzimanoglou A, Brashear A, Clapcote SJ, Gurrieri F, Goldstein DB, et al. Distinct neurological disorders with ATP1A3 mutations. Lancet Neurol. 2014 May;13(5):503-14.

18. Rosewich H, Ohlenbusch A, Huppke P, Schlotawa L, Baethmann M, Carrilho I, et al. The expanding clinical and genetic spectrum of ATP1A3-related disorders. Neurology. 2014 Mar 18;82(11):945-55.

19. Rosewich H, Sweney MT, DeBrosse S, Ess K, Ozelius L, Andermann E, et al. Research conference summary from the 2014 International Task Force on ATP1A3Related Disorders. Neurol Genet. 2017 Apr;3(2):e139.

20. Panagiotakaki E, De Grandis E, Stagnaro M, Heinzen EL, Fons C, Sisodiya S, et al. Clinical profile of patients with ATP1A3 mutations in Alternating Hemiplegia of Childhood-a study of 155 patients. Orphanet J Rare Dis. 2015 Sep 26;10:123.

21. Nicolaides P, Appleton RE, Fryer A. Cerebellar ataxia, areflexia, pes cavus, optic atrophy, and sensorineural hearing loss (CAPOS): a new syndrome. J Med Genet. 1996 May;33(5):419-21.

22. Maas RPPWM, Schieving JH, Schouten M, Kamsteeg E-J, van de Warrenburg BPC. The Genetic Homogeneity of CAPOS Syndrome: Four New Patients With the c.2452G>A (p.Glu818Lys) Mutation in the ATP1A3 Gene. Pediatr Neurol. 2016 Jun;59:71-75.e1. 23. Viollet L, Glusman G, Murphy KJ, Newcomb TM, Reyna SP, Sweney M, et al. Alternating Hemiplegia of Childhood: Retrospective Genetic Study and GenotypePhenotype Correlations in 187 Subjects from the US AHCF Registry. PLoS ONE. 2015;10(5):e0127045.

24. McGrail KM, Phillips JM, Sweadner KJ. Immunofluorescent localization of three $\mathrm{Na}, \mathrm{K}-\mathrm{ATPase}$ isozymes in the rat central nervous system: both neurons and glia can express more than one Na,K-ATPase. J Neurosci. 1991 Feb;11(2):381-91.

25. Sugimoto H, Ikeda K, Kawakami K. Heterozygous mice deficient in Atp1a3 exhibit motor deficits by chronic restraint stress. Behav Brain Res. 2014 Oct 1;272:100-10.

26. Carecchio M, Zorzi G, Ragona F, Zibordi F, Nardocci N. ATP1A3-related disorders: An update. Eur J Paediatr Neurol. 2018 Mar;22(2):257-63.

27. Ovchinnikov YuA null, Monastyrskaya GS, Broude NE, Ushkaryov YuA null, Melkov AM, Smirnov YuV null, et al. Family of human Na+, K+-ATPase genes. Structure of the gene for the catalytic subunit (alpha III-form) and its relationship with structural features of the protein. FEBS Lett. 1988 Jun 6;233(1):87-94.

28. Sorkaç A, Alcantara IC, Hart AC. In Vivo Modelling of ATP1A3 G316S-Induced Ataxia in C. elegans Using CRISPR/Cas9-Mediated Homologous Recombination Reveals Dominant Loss of Function Defects. PLoS ONE. 2016;11(12):e0167963.

29. Rodacker V, Toustrup-Jensen M, Vilsen B. Mutations Phe785Leu and Thr618Met in $\mathrm{Na}+\mathrm{K}+$-ATPase, associated with familial rapid-onset dystonia parkinsonism, interfere with $\mathrm{Na}+$ interaction by distinct mechanisms. J Biol Chem. 2006 Jul 7;281(27):18539-48. 30. Einholm AP, Toustrup-Jensen MS, Holm R, Andersen JP, Vilsen B. The rapid-onset dystonia parkinsonism mutation $\mathrm{D} 923 \mathrm{~N}$ of the $\mathrm{Na}+\mathrm{K}+$-ATPase alpha3 isoform disrupts $\mathrm{Na}+$ interaction at the third $\mathrm{Na}+$ site. J Biol Chem. 2010 Aug 20;285(34):26245-54.

31. Toustrup-Jensen MS, Einholm AP, Schack VR, Nielsen HN, Holm R, Sobrido M-J, et al. Relationship between intracellular $\mathrm{Na}+$ concentration and reduced $\mathrm{Na}+$ affinity in $\mathrm{Na}+\mathrm{K}+-\mathrm{ATPase}$ mutants causing neurological disease. J Biol Chem. $2014 \mathrm{Feb}$ 7;289(6):3186-97.

32. Hunanyan AS, Helseth AR, Abdelnour E, Kherallah B, Sachdev M, Chung L, et al. Mechanisms of increased hippocampal excitability in the Mashl+/- mouse model of $\mathrm{Na}+$ /K+ -ATPase dysfunction. Epilepsia. 2018;59(7):1455-68. 
33. Roenn CP, Li M, Schack VR, Forster IC, Holm R, Toustrup-Jensen MS, et al. Functional consequences of the CAPOS mutation E818K of Na+,K+-ATPase. J Biol Chem. 2019 Jan 4;294(1):269-80.

34. Kaneko M, Desai BS, Cook B. Ionic leakage underlies a gain-of-function effect of dominant disease mutations affecting diverse P-type ATPases. Nat Genet. 2014 Feb;46(2):144-51. 
Table 1 Patients reports

\begin{tabular}{|c|c|c|c|c|c|c|c|c|c|c|c|c|c|c|}
\hline Patient & \multicolumn{3}{|c|}{1} & \multicolumn{3}{|c|}{2} & \multicolumn{2}{|c|}{3} & 4 & \multicolumn{2}{|c|}{5} & 6 & 7 & 8 \\
\hline Sex & \multicolumn{3}{|c|}{$F$} & \multicolumn{3}{|c|}{$\mathrm{M}$} & \multicolumn{2}{|c|}{$M$} & $\mathrm{~F}$ & \multicolumn{2}{|c|}{$\mathrm{F}$} & $\mathrm{F}$ & $\mathrm{F}$ & $\mathrm{F}$ \\
\hline ATP1A3 & \multicolumn{3}{|c|}{ c.2267G $>A$} & \multicolumn{3}{|c|}{ c.2267G $>A$} & \multicolumn{2}{|c|}{ c. $2267 G>A$} & c.2266C >T & \multicolumn{2}{|c|}{ c. $2267 \mathrm{G}>\mathrm{A}$} & c. $2266 \mathrm{C}>\mathrm{T}$ & c. $2267 \mathrm{G}>\mathrm{A}$ & c.2267G $>A$ \\
\hline Variant & \multicolumn{3}{|c|}{ p.Arg756His } & \multicolumn{3}{|c|}{ p.Arg756His } & \multicolumn{2}{|c|}{ p.Arg756His } & p.Arg756Cys & \multicolumn{2}{|c|}{ p.Arg756His } & p.Arg756Cys & p.Arg756His & p.Arg756His \\
\hline Family history & & & & & & & & & Mother & & & & Mother & Mother \\
\hline $\begin{array}{l}\text { psychomotor } \\
\text { development } \\
\text { before the first }\end{array}$ & \multicolumn{3}{|c|}{ Normal } & \multicolumn{3}{|c|}{ Normal } & \multicolumn{2}{|c|}{ Normal } & Normal & \multicolumn{2}{|c|}{ Normal } & Normal & $\begin{array}{c}\text { Congenital } \\
\text { ataxia }\end{array}$ & $\begin{array}{l}\text { Intention } \\
\text { tremor }\end{array}$ \\
\hline Decompensation & 1 & 2 & 3 & 1 & 2 & 3 & 1 & 2 & 1 & 1 & 2 & 1 & 1 & 1 \\
\hline $\begin{array}{l}\text { Age at the event } \\
\text { (year.month) }\end{array}$ & 1.9 & 4.6 & 4.10 & 1.5 & 2.0 & 6.5 & 1.4 & 3.4 & 5.6 & 2.0 & 3.0 & 2.2 & 3.6 & 5.0 \\
\hline Symptoms & & & & & & & & & & & & & & \\
\hline during the & + & + & + & + & + & + & + & + & + & + & + & + & + & + \\
\hline Hypotonia & + & & + & + & + & & + & + & & & & + & + & + \\
\hline Areflexia & + & + & + & + & + & + & & & & & & & & \\
\hline
\end{tabular}




\begin{tabular}{|c|c|c|c|c|c|c|c|c|c|c|c|c|c|c|}
\hline Ataxia & & + & + & + & + & + & + & + & & $\begin{array}{lll}+ & & \\
\end{array}$ & + & & $\begin{array}{lll}+ & & \\
\end{array}$ & + \\
\hline Chorea & & & & & + & + & + & + & & & & & & + \\
\hline Dystonia & & & & & & & + & + & & & & & & \\
\hline Dysarthria & & + & + & & + & + & + & & & & + & $\begin{array}{lll}+ & & \\
\end{array}$ & $\begin{array}{lll}+ & & \\
\end{array}$ & + \\
\hline Mutism & & & + & + & & & & + & + & & & & & \\
\hline Dysphagia & & & + & & & & + & + & + & & & + & & \\
\hline $\begin{array}{c}\text { Altered } \\
\text { consciousness }\end{array}$ & & & & & & & + & & & & & & & \\
\hline $\begin{array}{c}\text { Motor } \\
\text { impairments }\end{array}$ & & & & + & & & + & & & & & + & & \\
\hline $\begin{array}{c}\text { Abnormal eye } \\
\text { movements }\end{array}$ & & & & & & & & + & & & & & + & \\
\hline Bradykinesia & & & & & & & & + & & & & & & \\
\hline $\begin{array}{c}\text { Complete } \\
\text { recovery after } \\
\text { the event }\end{array}$ & + & & & + & & & + & & & & & & + & \\
\hline
\end{tabular}


Table 2: Literature case reports

\begin{tabular}{|c|c|c|c|c|c|c|c|c|c|c|c|}
\hline Reference & 7 & 8 & 6 & 11 & 12 & 9 & 10 & 13 & 13 & 13 & 14 \\
\hline $\begin{array}{c}\text { Publication } \\
\text { year }\end{array}$ & 2012 & 2014 & 2015 & 2016 & 2016 & 2016 & 2017 & 2017 & 2017 & 2017 & 2018 \\
\hline $\begin{array}{c}\text { Number of } \\
\text { patient }\end{array}$ & 1 & 1 & 1 & 1 & 1 & 1 & 3 & 1 & 3 & 2 & 1 \\
\hline Sex & $\mathrm{F}$ & $F$ & $\mathrm{~F}$ & $M$ & $\mathrm{~F}$ & $\mathrm{~F}$ & $\mathrm{~F} / \mathrm{F} / \mathrm{F}$ & $\mathrm{F}$ & $\mathrm{F} / \mathrm{F} / \mathrm{F}$ & $\mathrm{F} / \mathrm{F}$ & $M$ \\
\hline ATP1A3 & c.2267 & c.2267 & c.2266 & c.2266 & c.2266 & c.2266 & c.2267 & c.2267 & c.2267 & c.2267 & c.2266 \\
\hline variant & $\mathrm{G}>\mathrm{A}$ & $\mathrm{G}>\mathrm{A}$ & $C>T$ & $C>T$ & $C>T$ & $C>T$ & $\mathrm{G}>\mathrm{A}$ & $G>A$ & $\mathrm{G}>\mathrm{A}$ & $G>T$ & $C>T$ \\
\hline Family history & + & - & + & - & - & + & + & - & + & + & - \\
\hline $\begin{array}{c}\text { Normal } \\
\text { development }\end{array}$ & + & NA & + & - & + & + & $-/-/+$ & + & $+/+/+$ & $+/+$ & + \\
\hline $\begin{array}{l}\text { Number of } \\
\text { episodes }\end{array}$ & 3 & 2 & 4 & 4 & 3 & 1 & $2 / 2 / 1$ & 2 & $2 / 1 / 2$ & $2 / 2$ & 4 \\
\hline $\begin{array}{l}\text { Age at the } \\
\text { first episode } \\
\text { (year.month) }\end{array}$ & 0.9 & 0.9 & 1.1 & 1.5 & 0.11 & 0.9 & $5.0 / 2.6 / 0.8$ & 1.1 & $2.6 / 2.6 / 3$ & $1.9 / 1.9$ & 0.9 \\
\hline $\begin{array}{l}\text { Residual } \\
\text { phenotype }\end{array}$ & $\begin{array}{l}\text { Ataxia } \\
\text { Dysarthria } \\
\text { Dysphagia } \\
\text { Seizures }\end{array}$ & $\begin{array}{l}\text { Hypotonia } \\
\text { Dysarthria } \\
\text { Myoclonus } \\
\text { Choreodystoni } \\
\text { a }\end{array}$ & $\begin{array}{c}\text { Ataxia } \\
\text { Dysarthria } \\
\text { Dystonia }\end{array}$ & $\begin{array}{l}\text { Hypotonia } \\
\text { Dysarthria } \\
\text { Dystonia } \\
\text { Choreoathetosi } \\
\text { s }\end{array}$ & $\begin{array}{c}\text { Ataxia } \\
\text { Dystonia }\end{array}$ & $\begin{array}{c}\text { Ataxia } \\
\text { Choreodystonia } \\
\text { Dysarthria }\end{array}$ & $\begin{array}{l}\text { Ataxia, Dysarthria, } \\
\text { Choreoathetosis, } \\
\text { Dystonia/ } \\
\text { Ataxia, Dysarthria / } \\
\text { Ataxia }\end{array}$ & $\begin{array}{l}\text { Hypotonia } \\
\text { Chorea }\end{array}$ & $\begin{array}{c}\text { Dysphagia, } \\
\text { Hypotonia, Ataxia } \\
\text { Hypotonia, Ataxia } \\
\text { / } \\
\text { Dysarthria, Ataxia }\end{array}$ & $\begin{array}{l}\text { Hypotonia, Ataxia, } \\
\text { Chorea / } \\
\text { Hypotonia, Ataxia, } \\
\text { Chorea }\end{array}$ & $\begin{array}{l}\text { Ataxia } \\
\text { Dystonia } \\
\text { Choreoathetosis } \\
\text { Dysarthria } \\
\text { Hypotonia }\end{array}$ \\
\hline
\end{tabular}


Normal development: Normal psychomotor development before the first episode; NA: Not available 